DOI: $10.20472 / B M .2016 .4 .2 .004$

\title{
IT'S ALL ABOUT ME: AN EXPLORATION OF GENERATION Y'S PERCEPTIONS OF JOB CHOICE, TRAITS, VALUES, AND WORK RELATIONSHIPS IN THE SERVICE SECTOR
}

\section{ROBERT LEWIS}

\begin{abstract}
:
Generation Y refers to people born approximately between 1980 and 2000. This paper evaluates findings from in-depth interviews with seven generation $Y$ employees in the hospitality sector. Participants in this study revealed that job choice can be associated with symbolic encounters. Generation Y-related traits, such as the need for immediacy and increased feedback, were confirmed in discussions. In addition, participants' value sets took precedence over those of their employers in some cases. Findings also revealed insight on participants' understanding of culture at work and gender roles. Conceptually, this paper sheds light on the benefits of investigating people's identities through their experiences to better understand generational mind sets at work and to gain insight into the effects of generation $Y$ employees on practice.
\end{abstract}

\section{Keywords:}

Generation Y, Hospitality, Work Experiences

JEL Classification: $J 29$

\section{Authors:}

ROBERT LEWIS, Les Roches Gruyère University of Applied Sciences, Switzerland, Switzerland, Email: ralewis@gmail.com

\section{Citation:}

ROBERT LEWIS (2016). It's all about me: an exploration of generation Y's perceptions of job choice, traits, values, and work relationships in the service sector. International Journal of Business and Management, Vol. IV(2), pp. 42-55., 10.20472/BM.2016.4.2.004 


\section{Introduction}

There is a consensus in the literature that generation $Y$ refers to a co-hort (Twenge, Campbell, Hoffman and Lance, 2010) of people born between 1980 and 2000 (Erickson, 2008; Fenich, ScottHalsell and Hashimoto, 2011; Ng, Schweitzer and Lyons, 2010; Twenge and Campbell, 2008). This generation has been identified through its behaviour in the workplace (Delcampo, Haggerty, Hanley and Knippel, 2011; Ng, Schweitzer and Lyons, 2010), and more particularly its interaction with older generations (Twenge, Campbell, Hoffman and Lance, 2010). Moreover, the study of generation $Y$ in the hospitality context has gained attention as this generation is increasingly present in the workforce (Gursoy, Maier and Chi, 2007). In order to more deeply understand the collective identity of generation $\mathrm{Y}$ in hospitality work, this paper discusses the effects of its experiences through replies received during in-depth interviews with seven generation $Y$ employees in situ, studied as one co-hort.

\section{$2 \quad$ Literature review}

\subsection{Generation Y's work attitudes in hospitality sector functions}

Several studies have focused on the attitudes of generation $\mathrm{Y}$ in terms of its work values (Delcampo et al., 2011; Twenge, Campbell, Hoffman and Lance, 2010), such as being 'self-centred' (Erickson, 2008). Twenge, Campbell, Hoffman and Lance (2010) found that generation $Y$ has decreased involvement with work. Involvement refers to perceived proximity with work as a concept. There is also a decreased involvement with work because of generation Y's social values. Work-related attitudes, which are reflected through perceived involvement with work, can also be altered according to Bharath et al. (2008). This same research reveals that generation Y's work attitudes in the hospitality sector can become more positive with increased age and experience, which suggests an alteration of attitudes over time.

Current understandings of generation Y's values are incomplete because investigations have focused on the role of values shown only in the work environment (ibid). This suggests that there is a need to further probe not only into generation Y's perceived work-related values, but also into perceived values in other spheres (e.g., work- versus non-work spheres) where they are also expressed. There is a consensus in the literature that generation Y's values have emphasised independence and life-related repercussions of work (Barron, Maxwell, Broadbridge and Ogden, 2007; Delcampo et al., 2011; Twenge, Campbell, Hoffman and Lance, 2010), such as work-life balance perceptions. The above arguments denote that generation Y's work attitudes are composed of values that can be opaque.

A large intergenerational study revealed that generation Y's values should not be "overgeneralised" (Cennamo and Gardner, 2008, p. 891). Studies have also shown that generation $Y$ does not value the same levels of engagement at work compared to those of other generations (Cennamo and Gardner, 2008; Solnet, Kralj and Kandampully, 2012). These same studies have shown that generation $\mathrm{Y}$ has less intrinsic 'attachment' to employers and higher turnover intentions (twenge et al., 2010). Per Cennamo and Gardner (2008), these previous arguments can also be linked to the understanding of employees' 'fit' with organisational values. Studies have investigated this 'fit,' or congruence using qualitative methodological approaches. Due to generation Y's 
growing presence in the current hospitality workforce, it is beneficial to discuss deeper-embedded attitudes through generation Y's viewpoint, which is an approach of this paper.

\subsection{Generation Y's expectations from hospitality work}

The hospitality sector has brought industry-related issues that affect generation $\mathrm{Y}$ in the workplace to light (Gursoy, Maier and Chi, 2007). In the workplace, generation $Y$ has been confronted with a work context that is incongruous with many of its expectations. Work-related expectations, such as increased work-balance employment features (Erickson, 2008), contrast with conventional, traditional hospitality industry employment conditions. Generation $Y$ therefore challenges current perceptions of work and organisational structures that have been accepted hitherto as the norm. Multiple generations have worked together in same organisational structures in the past. Today, the multigenerational workplace reveals more distinctive differences related to the presence of generation Y (Delcampo et al., 2011).

Generational perceptions of work have been historically structured by formal hierarchy (Gursoy, Maier and Chi, 2007). One of generation Y's characteristics is its increased disregard for hierarchy (Erickson, 2008). Moreover, the introduction of generation $Y$ in the workplace has increased misunderstanding of its identity due to Information Technology (IT) 'connectedness' (ibid) and communication pattern preferences that are more virtual in addition to face-to-face (Bolton, Parasuraman, Hoefnagels, Michels, Kabaday, Gruber, Komarova, Loureiro and Solnet, 2013). This reveals simultaneous, increased use of non-face-to-face and face-to-face communication. The above arguments bring to light a schism between generation $Y$ work practices in the hospitality sector and habitual, traditional work environments. Moreover, studies also reveal a schism between work and social values (Delcampo et al., 2011; Twenge et al., 2010). This same research suggests that generation $Y$ can experience decreased involvement with work, due to its fragmented communication patterns.

\subsection{Recruitment and retention of generation $\mathrm{Y}$ in the hospitality sector}

Studies on hospitality employers' recruitment and retention of generation $Y$ employees have emphasised a lack of awareness of employee desires (Ng, Schweitzer and Lyons, 2010), despite being "the largest generation entering the workforce" (Luscombe, Lewis, and Biggs, 2012, p. 272). This debate has been the object of numerous studies focusing on how to better adapt recruitment strategies to generation Y's expectations (Solnet and Hood, 2008). Generation Y is also attracted to workplaces with high levels of interaction and feedback (ibid). This reinforces the schism between generation Y's career expectations and the hospitality industry's current employment conditions, which is highlighted in studies by Broadbridge, Maxwell and Ogden (2006).

Recruitment and retainment practices have not adapted to generation Y's expectations, despite the the concern of human resources practice to attract the most qualified employees in a 'service oriented' model (Solnet and Hood, 2008). This suggests that there is a conscious effort by employers to adjust its recruitment practice with generation Y's profile. Despite this, there is a perceived generation 'gap' in the workplace that has yet to be fully understood.

Recruitment has been centred on a model that assumes a large candidate pool (Lieven and Highhouse, 2003). Studies have also concentrated on organisational attributes (Terjesen, Vinnicombe and Freeman, 2007) the most desirable factors of an employer to attract generation $Y$. 
Other studies have emphasised the need to generate higher levels of retention for customer-contact staff (Michel, Kavanagh and Tracey, 2012), such as in hospitality work. The work environment, as an aspect of recruitment, is another dimension that has been the focus of studies (Delcampo et al., 2011; Harsha, Chacko, Williams and Schaffer, 2012). Previous examples suggest that the traditional recruitment paradigm in the hospitality sector (ibid) reposes on values that contrast with those of generation $\mathrm{Y}$.

\subsection{Generation Y's perceptions of work relationships}

Generation Y's understandings of work relationships underscore open communication, which can contrast with more hierarchical and formal communication patterns amongst older generations. This has been brought to light through the interaction of key actors (e.g., employees, colleagues, line managers) in the workplace (Myers and Sadaghiani, 2010). Communication patterns and their related features reveal deeper understanding of how work relationships are understood, notably through differences in communication (Delcampo et al., 2011; ibid). This is beneficial to highlight because studies have shown that generation $Y$ values work relationships (ibid). By contrast, other studies have posited that generation $\mathrm{Y}$ dislikes hierarchy and formality (Solnet, Kralj and Kandampully, 2012). The literature attempts to understand generational aspects of work relationships through empirical evidence, such as through the interpretation of interaction of people at work. However, this is limited by mental schemes that may become more apparent, and identifiable, through investigations using in-depth interviews, which is one aspect of the methodology used in the study for this paper.

An article by Martin (2005) suggests that generation $Y$ workers are "independent, entrepreneurial, need immediate feedback and expect of sense of accomplishment" (p. 39). There is a general argument that generation $Y$ workers' expectations are incongruous with those of other generations (i.e., older generations) because generation $Y$ possesses traits that are different from those previously-mentioned (Delcampo et al., 2011; ibid). The perceptions of generation $Y$ are also often misunderstood by their own managers (Eisner, 2004). As previously highlighted by Myers and Sadaghiani (2010), communication barriers illustrate this lack of understanding. Furthermore, generation Y's perceptions of work relationships are affected by explicit and implicit expectations. Outcomes of this misconception affect perceptions of work satisfaction and productivity (Myers and Sadaghiani, 2010), which both are inherent components of managerial relationships. The above arguments point out that generational-related perceptions of work relationships can be understood through organisational and social norms, which are overarching concepts in the literature covered. These norms influence understandings of generational identities, which form the conceptual basis of this paper.

\subsection{Research questions}

The following research questions emerged from the literature.

1) What attracts generation $Y$ to work in the hospitality sector?

2) What work attitudes characterise generation $Y$ in the hospitality sector?

3) How does generation $Y$ perceive its identity in the hospitality work context? 
This paper focuses on exploring these questions, and deriving key themes from them, during indepth interviews with seven generation $Y$ workers in service-related functions in the hospitality context.

\section{Methodology}

\subsection{Use of the first person in discussions in this paper and retrieval of quotes}

This paper is written in the first person when interpreting findings, with few exceptions. This approach is supported by the nature of this study's enquiry in two ways. Firstly, discussing roles of the researcher in qualitative research implies that I experience mental proximity with respondents. Secondly, from an interpretivist viewpoint, the mental processes that took place when evaluating data required me to put myself in the situation of study participants. This reflective process is also part of the method used to select quotes, from interview material. Quotes in this paper were also used in this study in the first person to 'bring to life' participants' experiences. Quotes were not used verbatim, but rather according to the notes that I took during interviews.

\subsection{Development of interviews}

During spring 2013, I started to contact potential participants using a snowball approach (Creswell, 2003) to expand my initial set of contact. I initially contacted three previous students, by email, with whom I had remained in contact after their studies. I was familiar with their profiles and job functions, at the time of data collection. In my email I requested for their voluntary participation. At the same time, I used a snowball approach. I asked them if they could contact other students from my previous classes, with similar profiles, and who would be interested in participating.

Approximately three weeks later I was able to confirm seven participants. I informed all participants at this time by email that their participation was voluntary and that they could choose to withdraw, without any pressure, from the study at any time. I also stated that their identities would remain confidential and that any quotes used would be anonymised. Moreover, I invited them to rectify/delete any information from final transcripts. I would thus not use any quotes in future publications that were not previously reviewed and accepted by participants. I also discussed in my email how I would proceed with interviews and provided details on the study's content and objectives. All participants who volunteered agreed to take part in the study.

Study, participants could be considered homogenous. Their commonalities include: education in hospitality management in a Swiss institution, international work experience in hospitality functions, at least bilingual (one language being English), and part of the generation $Y$ co-hort. Most participants were working in luxury hotels. Some were working in other hospitality-related functions. All were managers or in managerial training programmes.

I created an electronic spreadsheet to organise potential meetings times that I co-ordinated with my free time. I created several two-hour slots for each potential interview appointment in my timetable. I then proceeded to contact all study participants. I was able to confirm six appointments via Skype and one in-person. At this time I created a protocol document with questions, based on the literature reviewed, that I would use to guide my interviews. 
In my role as a facilitator, the protocol document would provide a flexible framework. It would allow me to explore themes during semi-structured interviews. The document that I created had the elements indicated below. I began interviews by discussing themes related to profile more-or-less in the order they appear. For other themes, I allowed the interview conversation to follow naturally and refer to the document as a reminder not to forget themes.

-Name

-Age

-Work experience

-Country of origin

-Country of residence

-Influences to work in a hospitality-related job

-Traits considered important for people doing the interviewee's job

-Values considered important for people doing the interviewee's job

-Perceptions on work relationships

-Closing and asking if there are any questions

\subsection{Data collection through semi-structured interviews}

Nearly all data were collected through semi-structured interviews. One interview took place inperson, five via Skype, and one with a handwritten questionnaire. The first interview went smoothly, despite having to get used to taking notes by hand. Participants were not comfortable with recording, so this option was appropriate. After three failed attempts to organise a Skype interview with one participant, due to schedule conflicts, I used open-ended questions in an on-line questionnaire. It took approximately one and one-half months to complete all interviews.

All interview transcriptions were keyed into electronic documents and reviewed for coherency. I proceeded by identifying themes through a sifting process (see Creswell, 2003). This process was carried out by going through all interview data as an aggregate to identify themes. Raw data, in transcripts, were sifted through several times to identify broad to more narrow themes. Once themes were defined, I was able to gain a better understanding of the meaning of replies. Quotes, or parts of quotes, were extracted and used in the form of Meaning Units, or MUs (Giorgi, 1994). The quotes selected in this paper were used in the following discussions as sources for discussions and to bring participants' perspectives 'to life.' Quotes used were selected for their insight, versus typicality due to occurence (or number of appearances in transcripts). This is supported by an inductive study approach, where quotes can vivify discussion and support interpretation of findings from people in situ.

All participants' identities were anonymised in quotes in this paper. Nevertheless, their work location (e.g., Respondent working in Europe) was used to situate them in discussions. Moreover, any sensitive elements, such as text that could reveal their identities, aspects unrelated to the study, including 'small talk,' were removed from quotes.

\subsection{Participant profiles}

The backgrounds of study participants were highly international, both as individuals and as a cohort. Their nationalities and continents where they had work experience are listed, in random order, below. 
- Chilean/French trained in Asia and Europe

- Mexican trained in Europe and Oceania

- Australian trained in Europe and Oceania

- British/Hong Kong Chinese trained in Asia and Europe

- Mexican trained in Asia and Europe

- German/Moroccan trained in Europe

- Czech trained in Asia and Europe

All interviews were held in English. Interviews took place (virtually, by email, and in-person) in the following locations (listed, in random order, below):

- Australia

- Chili

- England

- Hong Kong

- Switzerland

- USA

Study participants all had experience, previous to the study, in professional hospitality-related positions in at least two different countries. Participants also spoke at least two languages fluently. One mastered six. Participants showed interest in the study and a desire to share experiences. Through conversation, I felt increased proximity to participants. I do not know if it were because I had known them during their studies and they were eager to contribute to an academic exercise for their educational institution, or if they were curious to reveal their experiences as generation $Y$ professionals. Surprisingly, replies were candid and genuine. At the outset of all interview candidates shared, through anecdotal experience, insight into generation Y's perceptions of hospitality work. The themes, and their related insight, that emerged from these conversations form the following discussions.

\section{$4 \quad$ Findings}

\subsection{Importance of symbolic encounters}

Findings from participants reveal that common experiences, such as through travel and meeting people working in the hotel sector, can influence career choice, as portrayed below.

In my family, we used to travel a lot when I was a teenager, in Europe. I got to know hotels. I met a general manager in Greece, who went to a hotel school in Switzerland. He told me that Switzerland is the best place to study. I went on-line and looked at rankings of schools and visited all of the top ones. I felt it was difficult. (Respondent working in Europe)

These experiences can also have deeper repercussions. There are illustrations of career-related behaviours, such as those observed in people in the industry, family and cultural backgrounds, which epitomise values emphasised in findings. These values include caring and serving others. The finding below underscore an emphasis on the importance of interacting with other people, which is a facet of participants' interest in the hospitality sector, was initially generated. 
Family played a role. It is also part of my cultural background. This influences my attitude about being helpful and caring for others. These are key factors to consider. My father is in the medical profession so he is always serving people. (Respondent working in North America)

On a dimensional level, participants highlight the importance to be open-minded and to reach out to other people. Moreover, there is an apparent inner drive for professional and personal motivation to carry out service-related work, as the following quote exemplifies.

At the beginning of my studies I thought I would be a mechanical engineer. In my early studies at university I felt that I would have no chance. I felt that my skills matched something else. My best friend had become a duty manager in a hotel. He was friendly, open and handled complaints and wishes of guests. I had a first interview in a hotel to find out about doing that type of position here and stayed. (Respondent working in Europe)

Findings suggest a desire to solve problems to obtain related satisfaction when difficulties are resolved for guests. Overall, there is apparent preference to deal with more implicit tasks at work, such as interacting with other people and working in emotionally-laden situations. This aspect contrasts with studies by Delcampo et al. (2011) and Twenge et al. (2010), which suggest that these are undesirable features of service-related work.

\subsection{Recognition of generational value sets}

Findings suggest a need for constant feedback. There is a desire for interpersonal communication, through face-to-face and electronic methods. Moreover, communication patterns revealed use of synchronous (by simultaneously speaking, for example) and asynchronous (electronic message or by email, for example) methods. This underscores a generational gap that divides generation $Y$ with older generations, who do not use identical tools (see Cennamo and Gardner (2008)). The underlying argument suggests that the use of technology is not affected by the availability of it, but rather by a decision to use it. The finding below is one example.

My generation is similar, but I feel more mature than others. I think that my generation has a lot of exposure to internet technology. I find that at dinner the other night about $50 \%$ of them were texting or on Facebook. Technology has had a huge impact on how we act. We are reached by email and Facebook - and conversing over email. People at the office send too many emails, or calling, using instant messages. As a result our generation is adapted to it, quick to learn new things, new systems. Our generation is quite quick. One of our characteristics is the ability to adapt and learn quickly. One example is the use of Excelmy boss in his mid-40s is not so advanced. I created charts and tried teaching him but gave up. Somehow people my age learn these things quickly. (Respondent working in Asia)

From a dimensional perspective, findings show that there is a need for deeper understanding of how generation $Y$ communicates. Part of this understanding is drawn from generation Y's anecdotal experiences, and how those experiences are compared with those of older generations. Generation Y's communication patterns appear to be incongruous with those of older generations, despite the imposed, common, face-to-face communication context of work in hospitality, as illustrated by the following participant. 
Receiving and giving feedback. I really value that. For over four and one-half years at work, I have not received feedback. I would have liked it. I know how they feel about me and it is positive. My direct supervisor has told me, but not often enough. As a result, I manage six to seven people and approximately 15 casual staff. I try to give as much feedback as possible. It helps performance and communication - when giving feedback it is always verbal, not in text form. I think that it is more personal, intimate and professional when we sit down and converse. It is nice to receive thanks from the horse's mouth. I would hope that others in my generation feel the same way. (Respondent working in South America)

Inter-generational interaction can influence on the perceived value sets of generation $\mathrm{Y}$, such as the understanding of context-related communication style (such as the hospitality work context). This also assumes that there is an overlap between personal values and work values, which is suggested by Barron et al. (2007), Delcampo et al. (2011), and Twenge et al. (2010). Nevertheless, it remains uncertain if older generations adapt to the non-face-to-face communication tools used by generation $\mathrm{Y}$.

\subsection{Cultural effects}

Findings reveal that generation $Y$ can experience cognitive 'distance' in terms of perceived proximity with authority. Findings show that generation $\mathrm{Y}$ is aware of cultural influences of these perceptions, such as culturally-influenced hierarchical distance. These perceptions can also be at odds with organisational norms. However, there are unclear perceptions of the position of organisationally-related influences (such as those related to organisational norms) versus culturally-related influences (such as those related to national cultural norms) on work context. Despite this, cultural norms appear to be a significant force, illustrated in the below example of culturally-related behaviour of people in both work- and non-work- related contexts.

I do not think that a lot of other people in my generation act this way. Not generation $Y$, especially in my country. It is not a common cultural tradition to say something is good. There is not a lot of feedback in general here. However, young people here like it. They like the culture of feedback. The culture is more focused on the negative, but the positive needs to be noted too. In this culture, organisational culture is also different. Europeans and Americans do not hesitate to say thank you. People are different. (Respondent working in Asia)

It is uncertain if these perceptions are influenced by organisational norms, such as when organisational culture contrasts with national cultural norms. These findings contribute to understandings in the current literature, which does not discuss these two types of norms together in the same context.

In terms of dimensions that make up the understanding of cultural effects at work for generation $\mathrm{Y}$, findings emphasise a contextual shift. This means that there is an interest for generation $Y$ to increase face-to-face communication, even when there is a strong generationally-related tendency for non-face-to-face interaction. One surprising aspect of findings shows that generation $\mathrm{Y}$ is aware of these cultural parameters and understands that generationally-related behaviour can be altered, as portrayed in the quote below. 
Perceptions of hierarchy can also be cultural. My friend was with Chinese employees during an internship in China. He talked to the manager. The Chinese colleagues would never do that. The Chinese were punished for speaking to the manager, but nothing happened to my friend. He stated his opinion. In Korea too, younger students in my class who are amongst Korean students would position themselves within a hierarchy. In that way, even young people have to show respect to others (close in age). Here, in my country, hierarchy is closer in perception, if I compare things with more 'formal' cultures in other places. (Respondent working in South America)

This suggests a dichotomy in which there is a desire for proximity and maintenance of distance with respect to position/status at work. Findings show that the respect for cultural norms is deep-rooted. They complement the current debate in the literature on the roles of organisational attributes (Terjesen et al., 2007) such as those evaluated for this paper; neglect to discuss overarching effects of cultural influences at work. It is beneficial to understand how generation $Y$ perceive cultural norms related to its understanding of work- and non-work contexts.

\subsection{Gender-related effects}

It is unclear if findings reveal clear gender differences of generation $Y$ at work. Nevertheless, there is an overlapping influence of gender on perceptions of work relationships. There is a need to understand gender perceptions of generation $Y$ because these perceptions can reveal how generationally-related gender roles are perceived in work contexts. Being more 'outspoken' is one aspect of generation Y's identity that was illustrated in findings, as in the quote below.

Another manager's suggestions were ridiculous. When I spoke my mind I was humble. You have to be careful with your communication and being too 'open.' It is shocking for them (from other generations). The reason is based on my experiences and their reaction when I question things. I like to say that they could have thought of things differently, in a different way. It could also be sometimes that it comes from a female. (Respondent working in Oceania)

However, it is unclear if this perceived aspect of generation Y's identity can be related to gender. Due to the limited number of female participants in the co-hort, findings reveal limited insight. Nevertheless, findings suggest that generation Y's gender-related perceptions can be at odds with those of older generations.

Generation Y's understanding of male and female roles at work remain gender-perceived to some degree. This can be linked to generation Y's understanding of work-life balance and its relationship to family and work roles. It is unclear if generation $Y$ perceives more traditional views of gender, such as female versus male roles in family- and work-related contexts. This study revealed the value of understanding female perceptions of generation $\mathrm{Y}$ at work, and how gender can influence perceptions of interaction in the hospitality work context. This is depicted below.

Organisations have managers with average ages of over 50 too. That is an older generation. When it is confronted with a young generation $Y$ female, who is educated, and is coming out and questioning, they realise that it has never happened before. It happens a lot; more than we know about. (Respondent working in Oceania) 
This debate reveals that it is utilitarian to understand generationally-related gender effects in the hospitality work context.

\section{Conclusions}

\subsection{Generational identities remain opaque to some degree}

When exploring commonalities in findings, several aspects of participants' perceived identities came to light. There is an iterative process which allows generational identities to emerge through the observation and evaluation of intergenerational interaction. This suggests that through reflection, deeper understandings of findings can surface. These perceptions can become identifiable through the investigation of peoples' understandings, such as evaluating reflection from anecdotes. Findings show that generational identities can be more deeply understood through insight from participants' common experiences.

Identity can be perceived through the observation of generational differences through intergenerational interaction. The co-hort studied show awareness of their generational identities. This is re-inforced their mental 'separation' from other generations. These perceptions are nevertheless difficult to capture because study findings are based on only what participants voluntarily share. Nevertheless, this study's findings emphasise that generation $Y$ perceives its identity, in part, through its understanding of the common features that constitute generation $\mathrm{Y}$. This study shed light on the more implicit dimensions of this perceived identity.

All participants continued to interact with other generations (older generations) whilst holding on to their own value sets. At times, this took place in a confrontational fashion. I think that due to the presence of generation $Y$ in the workplace, there is a significant shift in how people see relationships in the workplace, often with emotionally-laden views. Generation $Y$ does not expect older generations to change. In the service sector, notably hotels, the current generation Y's perceptions of work relationships will also evolve as careers progress and employees interact with both older and younger generations. As the careers of the current generation $Y$ advance, this situation will become increasingly beneficial to more deeply understand. The investigation of generational understanding brings depth and richness in understanding the role of work in people's lives. It also helps us understand how social identity is perceived in the workplace through contrasting generational viewpoints.

\subsection{The understanding of generation Y's perceptions of work can affect employment practices in hospitality organisations}

Employment markets with an abundance of candidates will need to attract employees with increased non-monetary benefits. Examples include open communication channels, clear promotion schemes, flexible schedules and work-life balance benefits (for family-related needs). This will challenge the hospitality industry's tradition of maintaining long, often unsocial work patterns and the related sacrifice of personal time for workers. Current working conditions can thus be at odds with generation Y's perception of work-life balance and careers. This study brings unique insight into understandings of hospitality work contexts.

This paper posits that there are implications for managerial practice in contexts where multiple generations work together. The interaction of employees with their managers will most likely affect 
the employment environment, including the adjustment of organisational norms and working conditions. This reflection is based on the assumption that organisational contexts are shaped by the social actors within them. Nevertheless, it could also be expected that there will be resistance from traditional organisational cultures, which may still be influenced by people from generations previous to those of generation $\mathrm{Y}$. It could also be argued that organisational culture can influence generationally-perceived norms. The previous arguments suggest that interactions of different generations in the same workplace can generate changes in the work environment. More significantly, these changes affect the understanding of work context and the perceptions of work relationships.

For employers in employment markets with fewer qualified candidates, due to an increasingly ageing workforce (such as in the case of 'Baby boomers' (see Delcampo et al., 2011)), there will be an alteration of forces. Generally, I think that generation $Y$ employees in this cohort have made an informed decision in terms of career sector choice. However, due to the growth of hospitality sector jobs and an internationally mobile workforce, qualified candidates, unsurprisingly, will have increased choice for jobs. Employers will concentrate on making their organisational culture open, accessible, and adapted to generation Y's (or future generations') lifestyles. This situation could entail building relationships with future employees at younger ages (e.g., during studies and/or internships) to better understand their future career desires. This claim also assumes that organisations will have long-term commitments to workers. The understanding of job role perceptions from generation Y's perspective in the hospitality sector will benefit from research that probes more deeply, to better comprehend its mind set.

\section{$6 \quad$ Limitations}

This study did not attempt to generalise findings, but rather only provide insight through the exploration of experiences of a homogenous co-hort. This type of investigation is inherently limited by the cross-sectional investigation of a small number of respondents. Nevertheless, the in-depth exploration of one co-hort provided unique insight into professional experiences from Swisseducated generation $Y$ people all working in a similar context. In future studies, interviews could be less structured to allow the further identification of themes and pick up depth. Furthermore, a sample could be identified, in a first phase, to identify key factors that generation $Y$ workers in hospitality functions deem significant. In a second phase, factors could be explored during interviews with the same sample, or a larger one. To retrieve more insight on gender, genderrelated themes could be explored independently by asking the same questions to males and females versus an independent comparison of qualitative interview material from male and female participants.

\section{$7 \quad$ References}

Barron, P., Maxwell, G., Broadridge, A., Ogden, S. (2007), "Careers in Hospitality Management: Generation Y's Experiences and Perceptions," Journal of Hospitality and Tourism Management, Vol. 14, No. 2. http://dx.doi.org/10.1375/jhtm.14.2.119

Bolton, R., Parasuraman, A., Hoefnagels, A., Migchels, N., Kabadayi, S., Gruber, T., Komarova Loureiro, Y., Solnet, D. (2013), "Understanding Generation Y and their use of Social Media: a review and research agenda," Journal of Service Management, Vol. 24, No. 3. 
Broadridge, A., Maxwell, G., Ogden, S. (2006), "Retailing, Careers and Generation Y," Institute for Retail Studies Working Paper 0601.

Cennamo, L., Gardner, D. (2008), "Generational differences in work values, outcomes and personorganisation values fit," Journal of Managerial Psychology, Vol. 23, No. 8.

Chacko, H., Williams, K., Schaffer, J. (2012), "A Conceptual Framework for Attracting Generation Y to the Hotel Industry Using a Seamless Hotel Organizational Structure," Journal of Human Resources in Hospitality \& Tourism, Vol. 1, No. 2. http://dx.doi.org/10.1080/15332845.2012.648843

Creswell, J. (2003), Research Design, Sage, London.

Delcampo, R., Haggerty, L., Haney, M.-J., Knippel, L.-A. (2011), Managing The Multigenerational Workforce, Gower, Farnham.

Eisner, S. (2005), "Managing Generation Y," SAM Advanced Management Journal, autumn.

Erickson, T. (2008), Plugged in, the Generation Y Guide to Thriving at Work. Boston: Harvard Business Press.

Fenich, G., Scott-Halsell, S., Hashimoto, K. (2011), "An Investigation of Technological Uses by Different Generations as it Relates to Meeting and Events: A Pilot Study," Journal of Conventions and Event Tourism, Vol. 12.

Giorgi, A. (1994), "A Phenomenological Perspective on Certain Qualitative Research Methods," Journal of Phenomenological Research, Vol. 25, No. 2.

Gursoy, D., Maier, T., Chi, G. (2008), "Generational differences: An examination of work values and generational in the hospitality gaps in the hospitality workforce," International Journal of Hospitality Management, Vol. 27. http://dx.doi.org/10.1016/j.ijhm.2007.11.002

Josiam, B., Devine, F., Baum, T., Crutsinger, C., Reynolds, J. (2007), "Attitudes to Work of Generation Y Students in Hospitality Management: a comparative analysis of students in England, Scotland and Northern Ireland," Journal of Hospitality and Tourism Education, Vol. 22, No. 1.

Josiam, B. Reynolds, J., Thozhur, S., Crutsinger, C., Baum, T., Devine, F. (2008), "Attitudes to Work of Generation Y Students in Hospitality Management: A Comparative Analysis of Students in the United States and the United Kingdom," Journal of Foodservice Business Research, Vol. 11, No. 3. http://dx.doi.org/10.1080/15378020802317016

Lievens, F., Highhouse, S. (2003), "The relation of instrumental and symbolic attributes to a company's attractiveness as an employer," Personnel Psychology, Vol. 56, No. 1. http://dx.doi.org/10.1111/j.17446570.2003.tb00144.x

Luscombe, J., Lewis, I., Biggs, H. (2012), "Essential elements for recruitment and retention: Generation Y," Education + Training, Vol. 55, No. 3.

Martin, C. (2005), "From high maintenance to high productivity," Industrial and Commercial Training, Vol. 37, No. 1. http://dx.doi.org/10.1108/00197850510699965

Maxwell, G., Ogden, S., Broadbridge, A. (2010), "Generation Y's Career Expectations and Aspirations: Engagement in the Hospitality Industry," Journal of Hospitality and Tourism Management, Vol. 17. http://dx.doi.org/10.1375/jhtm.17.1.53

Michel, J., Kavanagh, M., Tracey, B. (2012), "Got Support? The Impact of Supportive Work Practices on the Perceptions, Motivation, and Behavior of Customer-Contact Employees," Cornell Hospitality Quarterly, Vol. 54, No. 2. 
Myers, K., Sadaghiani (2010), "Millenials in the Workplace: A Communication Perspective on Millenials' Organizational Relationships and Performance," Journal of Business Psychology, Vol. 25. http://dx.doi.org/10.1007/s10869-010-9172-7

Ng, E., Schweitzer, L., Lyons, S. (2010), "Got Support? The Impact of Supportive Work Practices on the Perceptions, Motivation, and Behavior of Customer-Contact Employees," Cornell Hospitality Quarterly, Vol. 54, No. 2.

Solnet, D., Hood, A. (2008), "Generation Y as Hospitality Employees: Framing a Research Agenda," Journal of Hospitality and Tourism Management, Vol. 15. http://dx.doi.org/10.1375/jhtm.15.59

Solnet, D., Kralj, A., Kandampully, J. (2012), "Generation Y Employees: An Examination of Work Attitude Differences," The Journal of Applied Management and Entrepreneurship, Vol. 17, No. 3.

Terjesen, S., Vinnicombe, S., Freeman, C. (2007), "Attracting generation Y graduates, organisational attributes, likelihood to apply and sex differences," Career Development International, Vol. 12, No. 6. http://dx.doi.org/10.1108/13620430710821994

Twenge, J., Campbell, S. (2008), "Generational differences in psychological traits and their impact on the workplace," Journal of Managerial Psychology, Vol. 23, No. 8.

Twenge, J., Campbell, S., Hoffman, B., Lance, C. (2010), "Generation Differences in Work Values: Leisure and Extrinsic Values Increasing, Social and Intrinsic Values Decreasing," Journal of Management, Vol. 36, No. 5. http://dx.doi.org/10.1177/0149206309352246 